\title{
Changes of surface energy partitioning caused by plastic mulch in a cotton field**
}

\author{
Zhipin Ai ${ }^{1,2}$, Yonghui Yang ${ }^{1}$, Qinxue Wang ${ }^{2}$, Shumin Han ${ }^{1}$, Yanmin Yang ${ }^{1}$, Quan Wang ${ }^{3}$, and Guoyu Qiu ${ }^{4}$ \\ ${ }^{1}$ Key Laboratory of Agricultural Water Resources, Hebei Laboratory of Agricultural Water-saving, Centre for Agricultural Resources \\ Research, Institute of Genetics and Developmental Biology, Chinese Academy of Sciences, Shijiazhuang 050021, China \\ ${ }^{2}$ Centre for Regional Environmental Research, National Institute for Environmental Studies, Tsukuba 305-8506, Japan \\ ${ }^{3}$ Faculty of Agriculture, Shizuoka University, Shizuoka 422-8529, Japan \\ ${ }^{4}$ School of Environment and Energy, Peking University, Shenzhen 518055, China
}

Received October 17, 2017; accepted March 23, 2018

\begin{abstract}
Widely used in croplands, plastic mulch can significantly change land surface properties and energy partitioning. However, the magnitude of these modifications caused by plastic mulch (and its variations) on leaf area index remain largely unclear. Field experiments were, therefore, conducted to analyse the differences in energy partitioning between plastic mulch and non-plastic mulch conditions in cotton fields in arid Tarim Basin. Each component net radiation, surface soil heat flux, sensible heat and latent heat was either measured or estimated at different growth stages of the cotton crop. Results showed that the effects of plastic mulch on field energy partitioning was most evident when leaf area index was less than 1.0. During this period, net radiation decreased mainly due to the increase of surface reflectance. Surface soil heat flux and sensible heat were also increased due to the increase of surface temperature. Finally, latent heat decreased after plastic mulch application. As over $20 \%$ of net radiation was allocated to the soil surface under plastic mulch at the seedling stage, this suggests that surface soil heat flux should not be ignored for evaluating surface energy balance at the seedling stage under plastic mulch conditions.

Keywords: land cover, land surface property, leaf area index, arid land
\end{abstract}

\section{INTRODUCTION}

Land surface energy partitioning is the process of partitioning net radiation into latent heat, sensible heat and surface soil heat flux at the earth/air boundary. The magnitude of each energy component is closely related to the physical properties of the land surface, which, in turn, has influence upon surface temperature, surface reflectance, roughness length and aerodynamic resistance (Horton et al.,

\footnotetext{
*Corresponding author e-mail: yonghui.yang@sjziam.ac.cn

**This work was funded by the Strategic Priority Research Program Pan-Third Pole Environment Study for a Green Silk Road (Pan-TPE: 4-3-2-3) from 2018 to 2022 and the Key Project (No. GJHZ1647) of Chinese Academy of Sciences from 2016 to 2018.
}

1996; Baldocchi and Meyers, 1998; Li et al., 2009). Thus, investigating the changes in energy partitioning caused by different agricultural mulching practices is crucial for a better understanding of surface energy and water balance in cropland ecosystems.

Plastic mulch is a cover technique that is widely used in croplands in arid and semiarid regions around the world due to its beneficial bio-environmental effects, which include weed suppression, yield increase and water use efficiency enhancement (Kasirajan and Ngouajio, 2012; Li et al., 2008; Tarara, 2000). However, the application of plastic mulch can significantly change the land surface characteristics and field micro-meteorological conditions (Ham et al., 1993; Tarara, 2000) that influence surface energy partitioning.

Through field observation, Liakatas et al. (1986) noted that plastic mulch increases both mean soil temperature and the amplitude of the daily soil temperature cycle at a soil depth of $2 \mathrm{~cm}$, and thereby increases soil heat flux relative to bare soil. Moreover, Bonachela et al. (2012) showed that daily net radiation at the bare soil surface is close to that at the surface of transparent plastic mulch under noncropped greenhouse conditions. In addition, Bussiere and Cellier (1994) observed that due to enhanced reflection of solar radiation and upward longwave radiation, net radiation reaching sugarcane residue mulch is $20 \%$ lower than that reaching bare soil. In contrast to bare soil, the maximum soil heat flux decreases by $63 \%$ under crop residue mulch, while maximum sensible heat increases by $300 \%$. Consequently, maximum latent heat decreases by $30 \%$. Using a heated foil technique to measure surface conductance in non-cropped plots, Tarara and Ham (1999) showed

(C) 2018 Institute of Agrophysics, Polish Academy of Sciences 
that the sensible heat of black plastic mulch is larger than that of bare soil. Indeed, a difference of about $150 \mathrm{~W} \mathrm{~m}^{-2}$ can be seen at midday. Although these studies reported the possible effects of plastic mulch on energy balance components for bare soil and greenhouse conditions, knowledge gaps still exist in real cropland situations. This is especially true for the missing knowledge of how these effects vary with leaf area index (LAI) during the full growth stage. Recently, the reported works such as those by $\mathrm{Li}$ et al. (2013), Yang et al. (2012), Ding et al. (2013), and Ai and Yang (2016) have focused on evapotranspiration estimation under plastic mulch conditions. These authors offer good reference for choosing appropriate methods to conduct energy partitioning analyses in such situations. What is notable is that these and many other studies were based solely on eddy covariance measurements under plastic mulch conditions - they lacked comparison with non-plastic mulch situations.

Therefore, this study was conducted to further explore the effects of plastic mulch on surface energy partitioning. It is based on comparative experiments between plastic mulched and non-plastic mulched treatments in a cotton field in Northwest China. The objective of this study is to investigate the changes in each component of energy balance induced by plastic mulch under different LAI conditions.

\section{MATERIALS AND METHODS}

Field experiments were conducted in 2014, at the Soil and Water Conservation Monitoring Station in Aksu Oasis, near Aler City, in the Tarim River Basin. Detailed information on the study site can be found at Ai and Yang (2016). Two drip irrigation treatments, one with plastic mulch
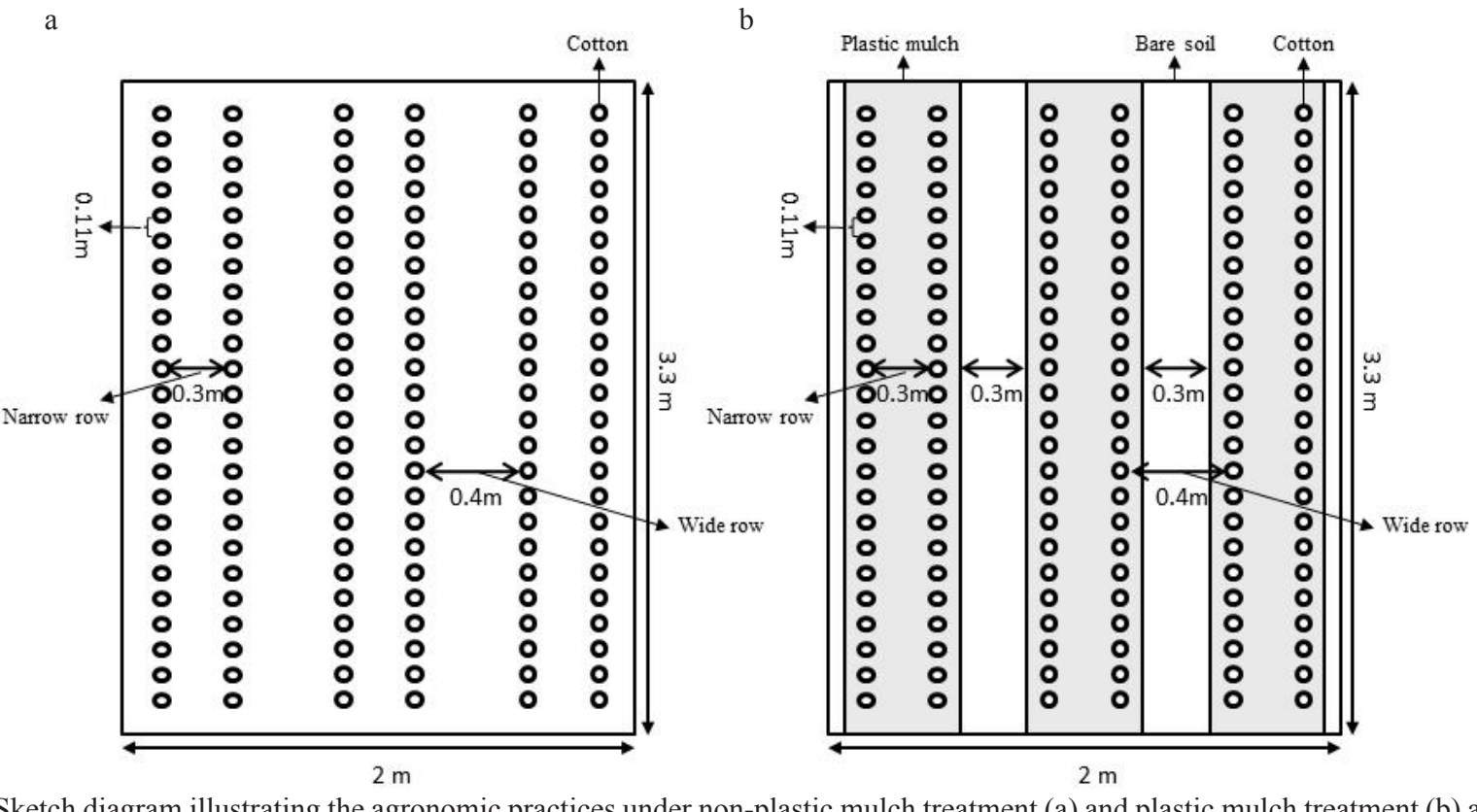

Fig. 1. Sketch diagram illustrating the agronomic practices under non-plastic mulch treatment (a) and plastic mulch treatment (b) at the Soil and Water Conservation Monitoring Station, in the Aksu Oasis, in the Tarim River Basin, Northwest China.

(PM) and the other without mulch (NM), were set up on day of the year (hereafter DOY) 118 in 2014. A sketch diagram illustrating the agronomic practices under NM and PM treatment is presented in Fig. 1. In each treatment, cotton (Gossypium hirsutum L., Xinluzhong-37) was planted at row spacing of $0.3 \mathrm{~m}$, plant spacing of $0.11 \mathrm{~m}$, and population density of about 26 plants per $\mathrm{m}^{2}$. Each row was oriented in the east-west direction. There were a total of 6 rows per treatment, which were divided into narrow rows and wide rows based on the row spacing. Two nearest row widths of 0.3 and $0.4 \mathrm{~m}$ were defined as narrow row and wide row, respectively. An 11-emitter drip tape was placed in the centre of each narrow row of each treatment in the east-west direction. In the PM treatment, each narrow row and a drip tape were covered with a $3.30 \mathrm{~m}$ long and $0.50 \mathrm{~m}$ wide transparent polyethylene plastic film tightly pegged into the soil at the edges. At each side of the narrow row, $0.05 \mathrm{~m}$ of plastic film was buried vertically into the soil at a depth of $0.03 \mathrm{~m}$. The width of pure bare soil between two successive plastic films was $0.3 \mathrm{~m}$. The area under plastic mulch was about $60 \%$ of the total treatment area under the PM treatment (Fig. 1). The irrigation schedule and measurement of soil moisture and LAI can also be found at $\mathrm{Ai}$ and Yang (2016).

In each treatment, net radiation was measured using a net radiometer (PC-2, Jinzhou solar Scientific Ltd., China) mounted horizontally at $0.3 \mathrm{~m}$ above the cotton canopy and adjusted in relation to cotton height at different growth stages. The radiometers were fitted with a set of upward sensors for measuring incident shortwave and longwave radiation, and with a set of downward sensors for measuring reflected shortwave and longwave radiation. To obtain soil heat flux, two heat flux plates (HFP01-L33, Hukseflux, 
Netherlands) were placed in each treatment at $5 \mathrm{~cm}$ below the soil surface. One was placed at the centre of the middle narrow row and the other at the centre of pure bare soil between two successive plastic films. A spatial image of the variations in temperature (canopy temperature, bare soil surface temperature and plastic mulched surface temperature) in each treatment was generated using a mobile Infrared Camera (R300, NEC Ltd., Japan) at a height of $1.6 \mathrm{~m}$ at the cotton seedling stage. Canopy temperature was also measured by a R300 Infrared Camera while mulched, while bare soil surface temperatures were measured by a soil temperature probe (107-L33, Campbell Scientific Ltd., USA) as substrate surfaces were covered by cotton leaves at the other growth stages. The above data for the energy components were collected at two hourly intervals from 6 a.m. to 6 p.m. local time (LT). Similar to Li et al. (2015), data at 6 a.m. and 6 p.m. LT were excluded in the analysis of energy partitioning in order to control the data quality. Air temperature, relative humidity, and wind speed were measured using a self-build automatic meteorology station at a height of $2.0 \mathrm{~m}$ above the cotton field surface with a frequency of $30 \mathrm{~min}$. The station was placed directly on the side of the plots. The distance between the station and the plots was only around $50 \mathrm{~cm}$. Soil temperature was measured by the soil temperature probe at $0,5,10,20$, and $40 \mathrm{~cm}$ below mulched middle narrow row and pure bare soil between two successive plastic films. For the $0 \mathrm{~cm}$ soil temperature, the temperature probe was buried in a very thin soil layer to avoid exposing the sensor to air. A data logger (CR3000, Campbell Scientific Ltd., USA) was used to collect the raw data. Data for eight representative clear days (DOY 139, DOY 153, DOY 156, DOY 166, DOY 177 , D0Y 190, DOY 239, and DOY 269) in 2014 under different LAI conditions were used to calculate each component of the energy balance. The detailed information on the calculation methods can be found in the supporting information file. Wind speed, water vapour deficit, relative humidity and air temperature on the eight days are depicted in Fig. S1 in the supporting information file. Of note, we found that wind speed, VPD, and air temperature were relatively high on DOY 139, DOY 153 and DOY 166. In contrast, relative humidity was relatively low for these days. Overall, the meteorological conditions at the mentioned three days contributed more to evaporation than did the rest of the days.

\section{RESULTS}

Daytime variations in net shortwave radiation, net longwave radiation, and net radiation above the cotton canopy under both the PM and NM treatments at different cotton growth stages are plotted in Fig. 2. Due to higher surface albedo, net shortwave radiation at the seedling stage was obviously lower under PM than under NM treatment on DOY 139, DOY 153 and DOY 156. Due to higher surface temperature, net longwave radiation at the seedling stage was more negative under PM than under NM treatment on DOY 139, DOY 153 and DOY 156. As net radiation is the sum of net shortwave and longwave radiation, it was lower under PM than under NM treatment at the seedling stage (Fig. 2, right plot). The maximum difference in net radiation between PM and NM was about $64 \mathrm{~W} \mathrm{~m}^{-2}$, which occurred at 10 a.m. on DOY 153. Daytime variation in net radiation was similar to that in net shortwave radiation under both the PM and NM treatments. This was because the absolute value of net longwave radiation was very low, compared with that of net shortwave radiation. For instance, the maximum absolute value of net longwave radiation $\left(205 \mathrm{~W} \mathrm{~m}^{-2}\right)$ was far lower than net shortwave radiation under PM treatment $\left(684 \mathrm{~W} \mathrm{~m}^{-2}\right)$ on DOY 139 at 2 p.m. From DOY 166, net shortwave radiation, net longwave radiation and net radiation under the PM and NM treatments were similar.

Daytime variations in surface soil heat flux under the PM and NM treatments at different cotton growth stages are shown in Fig. 3. The plot reveals a rapid increase in surface soil heat flux under PM than under NM treatment between 8 a.m. and 12 a.m. After 2 p.m., the trend also dropped rapidly under PM treatment on DOY 139, DOY 156 and DOY 166, at the seedling stage. From 8 a.m. to 4 p.m., on DOY 190 and DOY 239 of the late squaring stage, surface soil heat flux in the two treatments was very similar. In general, the magnitude and thus amplitude of the surface soil heat flux decreased under both treatments with increasing LAI. For instance, the daily maximum surface soil heat flux under PM reached $260 \mathrm{~W} \mathrm{~m}^{-2}$ on DOY 139 $\left(\mathrm{LAI}=0\right.$ ), but dropped to $35 \mathrm{~W} \mathrm{~m}^{-2}$ at noontime on DOY $190(\mathrm{LAI}=3.2)$. The trend under the NM treatment was also similar to that under the PM treatment.

Theoretically, sensible heat is correlated positively with the difference between surface and air temperature, and negatively with aerodynamic resistance. In our study, we saw that daytime variations in total sensible heat under both treatments were different from those in net radiation and surface soil heat flux (Fig. 4). The irregular daytime dynamics were largely attributed to irregular variations in wind speed; a key aerodynamic resistance factor. For instance, wind speed on DOY 139 was $0.3 \mathrm{~m} \mathrm{~s}^{-1}$ at 12 a.m. and $2.4 \mathrm{~m} \mathrm{~s}^{-1}$ at 2 p.m. At this time, the corresponding sensible heat values were, respectively, 45 and $280 \mathrm{~W} \mathrm{~m}^{-2}$ under the PM treatment, and 29 and $180 \mathrm{~W} \mathrm{~m}^{-2}$ under the NM treatment. Sensible heat was apparently higher under the PM than under the NM treatment on DOY 139, DOY153, and DOY 156. The highest difference in sensible heat between the PM and NM treatments $\left(100 \mathrm{~W} \mathrm{~m}^{-2}\right)$ occurred at 2 p.m. on DOY 139, during the seedling stage. With increasing cotton growth and LAI, the difference narrowed down on DOY 153 and DOY 156, during the seedling stage, and on DOY 269, during the boll-opening stage. Sensible heat was also negative under the PM and NM treatments from DOY 166 , during the late seedling stage, to DOY 239, during the 


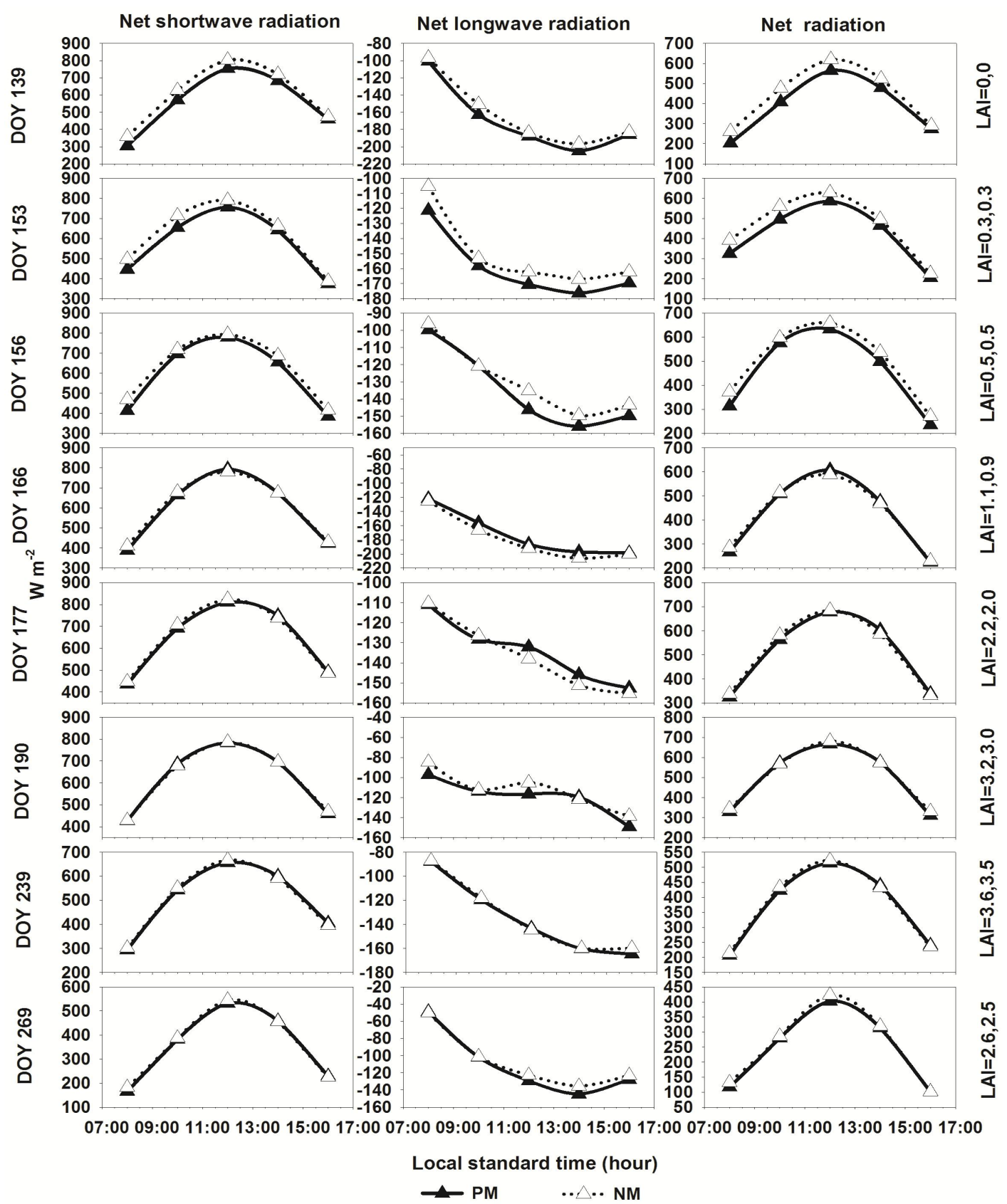

Fig. 2. Daytime variations in net shortwave radiation, net longwave radiation, and net radiation above cotton canopy under plastic mulch (PM) and non-plastic mulch (NM) treatments at different cotton growth stages. The two values of leaf area index (LAI) separated by commas are, respectively, for the PM and NM treatments.

flowering and boll-setting stages. This trend was attributed to low canopy temperature relative to air temperature during these growth stages.

Latent heat is the residual of the surface energy balance. As shown in Fig. 5, daytime variations in latent heat were similar for the PM and NM treatments, although it was generally lower for PM than NM on DOY 139, DOY 153 and DOY 156, at the seedling stage. For the three observation days at the seedling stage, mean hourly latent heat under the PM treatment was $138 \mathrm{~W} \mathrm{~m}^{-2}$. This was $56.3 \%$ of the
$246 \mathrm{~W} \mathrm{~m}^{-2}$ mean hourly latent heat under the NM treatment. The discrepancy was mainly due to the vertical flow of water and heat being blocked by plastic mulch. With increasing LAI after DOY 166, however, the difference in latent heat between the PM and NM treatments narrowed down, dropping to nearly $0 \mathrm{~W} \mathrm{~m}^{-2}$ at $2 \mathrm{p} . \mathrm{m}$. on DOY 190, at the squaring stage.

To gain further insight into the discrepancies in the energy partitioning between the PM and NM treatments, daily integrals of the energy balance components were 


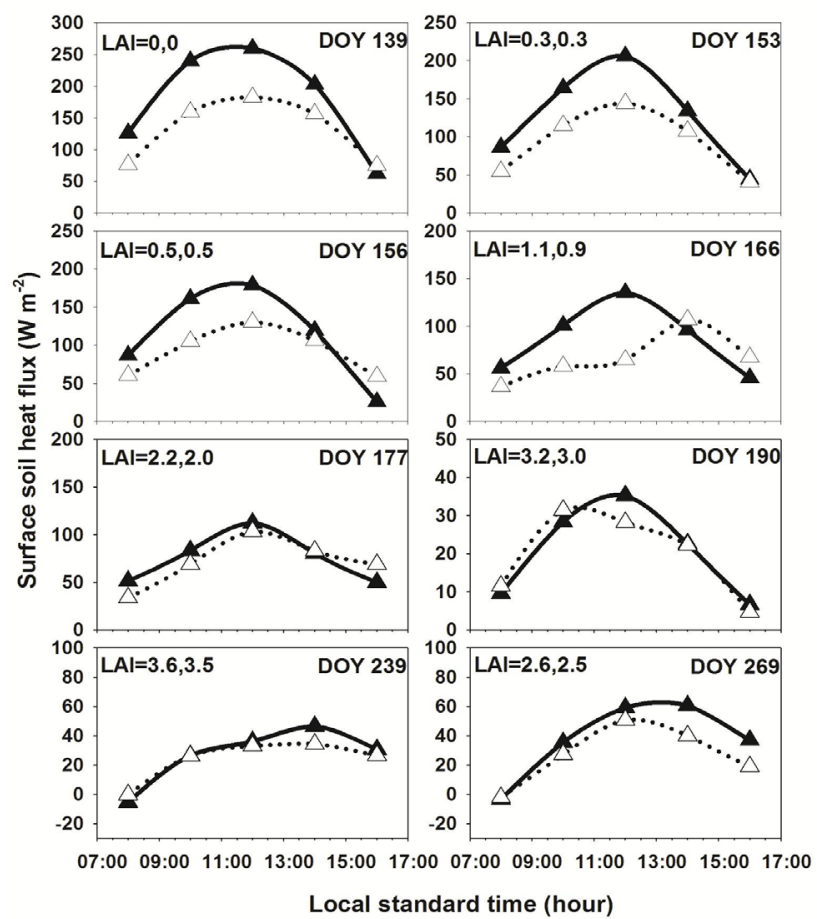

Fig. 3. Daytime variations in surface soil heat flux under plastic mulch (PM) and non-plastic mulch (NM) treatments at different cotton growth stages. The two values of leaf area index (LAI) separated by commas are, respectively, for the PM and NM treatments. Legend as in Fig. 2.

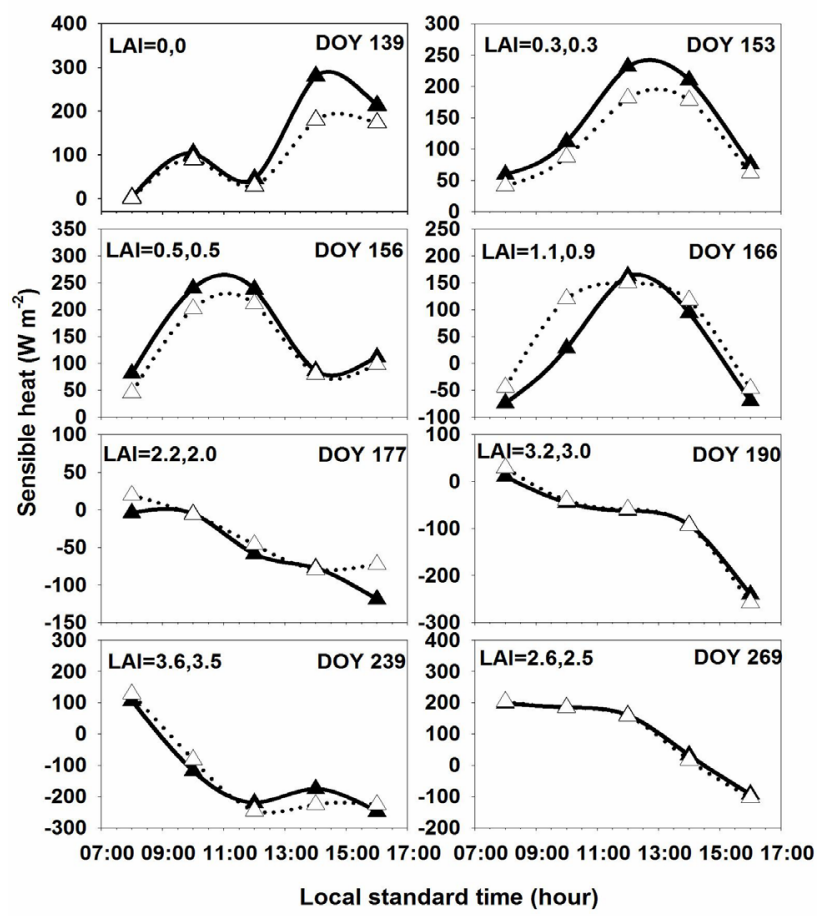

Fig. 4. Daytime variations in sensible heat under plastic mulch (PM) and non-plastic mulch (NM) treatments at different cotton growth stages. The two values of leaf area index (LAI) separated by commas are, respectively, for the PM and NM treatments. Legend as in Fig. 2.

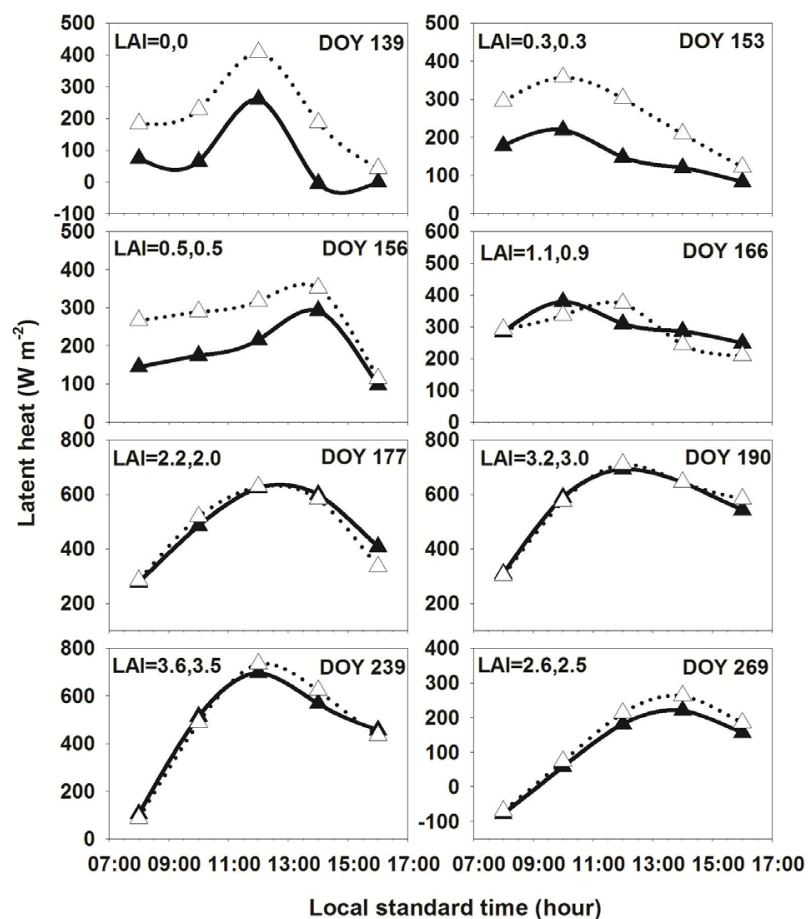

Fig. 5. Daytime variations in latent heat under plastic mulch (PM) and non-plastic mulch (NM) treatments at different cotton growth stages. The two values of leaf area index (LAI) separated by commas are, respectively, for the PM and NM treatments. Legend as in Fig. 2.

compared (Table 1). The decrease of available energy $\left(\mathrm{R}_{\mathrm{n}}-\right.$ $\mathrm{G})$ induced by plastic mulch was up to $3.48,2.86,2.11 \mathrm{MJ}$ $\mathrm{m}^{-2}$ day $^{-1}$ with an average of $2.82 \mathrm{MJ} \mathrm{m}^{-2}$ day $^{-1}$ (equalling to $22.0 \%$ ) at the early seedling stage (on DOY 139 , DOY 153 and DOY 156), respectively. Plastic mulch changes not only available energy reaching the soil surface, but also surface energy partitioning. At the early seedling stage (DOY 139, DOY 153 and DOY 156), increase in the ratio of surface soil heat flux relative to net radiation induced by plastic mulch was up to $0.16,0.11,0.06$, respectively. Similarly, the ratio of sensible heat relative to net radiation increased by $0.11,0.09$ and 0.08 under the PM treatment $(0.33,0.33$ and 0.34$)$ over that under the NM treatment $(0.22,0.24$ and 0.26 ) on DOY 139, DOY 153 and DOY 156, respectively. The maximum difference between PM and NM treatments in terms of the ratio of latent heat relative to net radiation reached 0.28 on DOY 139. Based on the average value for the three days of the seedling stage, the decrease in the ratio of latent heat relative to net radiation was up to 0.2 .

\section{DISCUSSION}

Incorporating LAI into energy partitioning analyses could significantly improve the accuracy of estimated energy components (Wang et al., 2014). Based on the observations and analysis in a series of LAI, this study showed that the effect of plastic mulch on energy partitioning in 
Table 1. Comparison of energy partitioning in plastic mulch (PM) and non-plastic mulch (NM) treatments at different cotton growth stages

\begin{tabular}{|c|c|c|c|c|c|c|c|c|}
\hline \multirow{2}{*}{$\begin{array}{l}\text { Growth } \\
\text { stage } \\
\text { DOY }\end{array}$} & \multicolumn{4}{|c|}{ Seedling } & \multicolumn{2}{|c|}{ Squaring } & \multirow{2}{*}{$\begin{array}{c}\begin{array}{c}\text { Flowering } \\
\text { and } \\
\text { boll-setting }\end{array} \\
\frac{239}{239}\end{array}$} & \multirow{2}{*}{$\begin{array}{c}\begin{array}{c}\text { Boll- } \\
\text { opening }\end{array} \\
269\end{array}$} \\
\hline & 139 & 153 & 156 & 166 & 177 & 190 & & \\
\hline LAI & $0 / 0$ & $0.3 / 0.3$ & $0.5 / 0.5$ & $1.1 / 0.9$ & $2.2 / 2.0$ & $3.2 / 3.0$ & $3.6 / 3.5$ & $2.6 / 2.5$ \\
\hline$G / R_{n}$ & $0.46 / 0.30$ & $0.31 / 0.20$ & $0.25 / 0.19$ & $0.21 / 0.16$ & $0.15 / 0.14$ & $0.04 / 0.04$ & $0.07 / 0.07$ & $0.16 / 0.11$ \\
\hline$H / R_{n}$ & $0.33 / 0.22$ & $0.33 / 0.24$ & $0.34 / 0.26$ & $0.07 / 0.14$ & $-0.07 / 0.95$ & $-0.17 /-0.17$ & $-0.36 /-0.35$ & $0.40 / 0.36$ \\
\hline$\lambda E / R_{n}$ & $0.20 / 0.48$ & $0.36 / 0.56$ & $0.41 / 0.55$ & $0.72 / 0.70$ & $0.95 / 0.93$ & $1.13 / 1.13$ & $1.28 / 1.29$ & $0.45 / 0.53$ \\
\hline$R_{n}-G$ & $7.49 / 10.98$ & $10.38 / 13.25$ & $12.13 / 14.24$ & $11.89 / 12.63$ & $15.35 / 15.59$ & $16.95 / 17.27$ & $12.16 / 12.37$ & $7.39 / 8.11$ \\
\hline
\end{tabular}

Values before and after the slash represent PM/NM treatments, respectively. The unit of net radiation $\left(R_{n}\right)$, surface soil heat flux $(G)$, sensible heat $(H)$, and latent heat $(\lambda E)$ is $\mathrm{MJ} \mathrm{m}^{-2}$ day $^{-1}$ and that of leaf area index (LAI) is $\mathrm{m}^{2} \mathrm{~m}^{-2}$.

cotton fields was most evident for LAI less than 1.0 at the seedling stage. Further analyses based on water balance between the PM and NM treatments confirmed this result (Fig. S2). As can be seen from Fig. S2, the difference in evapotranspiration between PM and NM treatments mainly occurred before DOY 167. During the seedling stage, the plastic film was much exposed to sunlight. Therefore, there was more reflection of radiation due to the high reflectance of plastic film. while net shortwave radiation was considerably reduced. As can be seen in Fig. S3, daily mean surface reflectance under the $\mathrm{PM}(\mathrm{NM})$ treatments was, respectively, $0.25(0.19)$ on DOY $139,0.24(0.18)$ on DOY 153, and $0.20(0.16)$ on DOY 156. This is similar to the observations by Fan et al. (2015), who found that surface reflectance increased on average by $27.9 \%$ when LAI was less than 1.0. On the other hand, net longwave radiation also dropped due to high longwave radiation away from the surface with increasing soil temperature, under plastic mulch conditions. Finally, net radiation available for partitioning also dropped. It is worth noting that the reduction in net radiation was mainly driven by the reduction in net shortwave radiation rather than in net longwave radiation. Since higher surface reflectance is often related to less available energy for evapotranspiration (Mehlitz et al., 2008), white plastic film mulch might be the best water-saving plastic film in croplands due to its capacity to limit available energy.

Around $34 \%$ of all net radiation was allocated to surface soil heat flux at the seedling stage, which indicated that the effect of plastic mulch on surface soil heat flux was critical in field energy balance partitioning analyses; at least at the early seedling stage (Heusinkveld et al., 2004). Sensible heat is positively correlated to differences in surface temperature and air temperature. As can be seen from Fig. S4, the differences in surface temperature and air temperature were higher under the PM than NM treatments, with an average of $2.4^{\circ} \mathrm{C}$ for DOY 139, DOY 153 and DOY 156.
Thus, plastic mulch increases sensible heat by increasing soil temperature. Based on the energy balance algorithm, latent heat decreased under the plastic mulch condition.

This study is primarily based on surface energy balance. This is the fundamental principle of the numerous models in relation to energy and mass exchange (Twine et al., 2000). Allen et al. (2011) underline that the remotely sensed energy balance method has the smallest errors in comparison with the method of eddy covariance, soil water balance and sap flow. The modified Shuttleworth and Wallace model developed by Li et al. (2013) has been noted to have good performance for plastic-mulched maize field, and which was, therefore, used to estimate sensible heat in this study. This method considered the effect of plastic mulch on sensible heat. Thus, the method used in this study was taken as being reliable in ascertaining the effects of plastic mulch on energy balance components.

In this study, the calibration uncertainty of shortwave and longwave radiation is lower than 1.5 and $7 \%$, respectively. The typical accuracy of the measurement of soil heat flux is within -15 to $5 \%$. Thus, as discussed by Twine et al. (2000), the errors from disparities in net radiation and surface soil heat flux were relatively small. Sensible heat might have the biggest errors in this study. The errors in the estimated sensible heat can be divided into two aspects: 1) the accuracy of the measurements in surface temperature, and 2) the estimated error in aerodynamic resistance and under plastic mulch condition. The measurement accuracy in air temperature, surface temperature, and canopy temperature are $\pm 1^{\circ} \mathrm{C}$. This figure is very acceptable. The aerodynamic resistance was estimated using the method developed by Li et al. (2013). In addition, we especially added the surface layer stability correction. The use of plastic mulch may change the aerodynamic resistance, but it is difficult to theoretically adjust this modification up to now. Moreover, Tarara and Ham (1999) observed that there were no significant differences in the aerodynamic resistance between plastic mulched surface and bare soil surface. 
Thus, the estimated sensible heat in this study, in our opinion, is acceptable. Of course, negative sensible heat was also observed on DOY 177, DOY 190, and DOY 239 for which days LAI exceeded 2.0, suggesting that more sensible heat was transferred from the surrounding air to the canopy layer. This was mainly due to lower canopy temperatures caused by high evapotranspiration in the large canopy structure. This phenomenon is also evident in nearby eddy covariance observations and other studies (Ai et al., 2018; Voogt and Grimmond, 2000; Watanabe and Mizutani, 1996).

\section{CONCLUSIONS}

This study fully presented the changes in the four components of energy budget in a cotton field with plastic mulch based on both observations and estimations. The main conclusion can be summarised as:

1. Plastic mulch not only changed the available energy, but also the energy partitioning.

2. The modifications in energy partitioning induced by plastic mulch were most evident at the seedling stage, when leaf area index was less than 1.0.

3. During this period, net radiation decreased mainly due to the increase of surface reflectance.

4. Surface soil heat flux and sensible heat increased due to the increase of surface temperature. Surface soil heat flux should not be neglected for evaluating surface energy balance at the seedling stage under plastic mulch conditions.

5. Due to the decrease of net radiation and the increase of sensible heat and surface soil heat flux, latent heat decreased after plastic mulching.

\section{ACKNOWLEDGEMENT}

We wish to express our great appreciation to Shaojie Bi, Huilong Li, Zhanyao Lü, Ping Wang, Mingfa Li, and Xiaogang Li for helping us with the field experiments. We also very much appreciate the helpful comments from Dr. Zhigang Sun.

Conflict of interest: The authors declare that they have no conflict of interest.

\section{REFERENCES}

Ai Z. and Yang Y., 2016. Modification and validation of Priestley - Taylor model for estimating cotton evapotranspiration under plastic mulch condition. J. Hydrometeor., 17, 1281-1293.

Ai Z., Yang Y., Wang Q., Manevski K., Wang Q., Hu Q., Eer D., and Wang J., 2018. Characteristics and influencing factors of crop coefficient for drip-irrigated cotton under plastic-mulched condition in arid environment. J. Agric. Meteor., 74, 1-8.
Allen R.G., Pereira L.S., Howell T.A., and Jensen M.E., 2011. Evapotranspiration information reporting: I. Factors governing measurement accuracy. Agric. Water Manag., 98, 899-920.

Baldocchi D. and Meyers T., 1998. On using eco-physiological, micrometeorological and biogeochemical theory to evaluate carbon dioxide, water vapor and trace gas fluxes over vegetation: a perspective. Agric. For Meteor., 90, 1-25.

Bonachela S., Granadosa M.R., Lópezb J.C., Hernándeza J., Magánb J.J., Baezab E.J., and Baillec A., 2012. How plastic mulches affect the thermal and radiative microclimate in an unheated low-cost greenhouse. Agric. For Meteor., 152, 65-72.

Bussière F. and Cellier P., 1994. Modification of the soil temperature and water content regimes by a crop residue mulch: experiment and modelling. Agric. For Meteor., 68, 1-28.

Ding R., Kang S., Li F., Zhang Y., and Tong L., 2013. Evapotranspiration measurement and estimation using modified Priestley-Taylor model in an irrigated maize field with mulching. Agric. For Meteor., 168, 140-148.

Fan X., Chen H., Xia X., and Yu Y., 2015. Increase in surface albedo caused by agricultural plastic film. Atmos. Sci. Lett., 16, 291-296.

Ham J.M., Kluitenberg G.J., and Lamont W.J., 1993. Optical properties of plastic mulches affect the field temperature regime. J. Amer. Soc. Hort. Sci., 118, 188-193.

Heusinkveld B.G., Jacobs A.F.G., Holtslag A.A.M., and Berkowicz S.M., 2004. Surface energy balance closure in an arid region: role of soil heat flux. Agric. For Meteorol., 122, 21-37.

Horton R., Bristow K.L., Kluitenberg G.J., and Sauer T., 1996. Crop residue effects on surface radiation and energy balance-review. Theor. Appl. Climatol., 54, 27-37.

Kasirajan S. and Ngouajio M., 2012. Polyethylene and biodegradable mulches for agricultural applications: a review, $\mathrm{M}$. Agron. Sustain. Dev., 32, 501-529.

Li S., Kang S., Li F., and Zhang L., 2008. Evapotranspiration and crop coefficient of spring maize with plastic mulch using eddy covariance in northwest china. Agric. Water Manag., 95, 1214-1222.

Li S., Kang S., Zhang L., Ortega-Farias S., Li F., Du T., Tong L., Wang S., Ingman M., and Guo W., 2013. Measuring and modeling maize evapotranspiration under plastic filmmulching condition. J. Hydrol., 503, 153-168.

Li S., Zhang L., Kang S., Tong L., Du T., Hao X., and Zhao P., 2015. Comparison of several surface resistance models for estimating crop evapotranspiration over the entire growing season in arid regions. Agric. For Meteor., 208, 1-15.

Li Z., Liu W.Z., Zhang X.C., and Zheng F.L., 2009. Impacts of land use change and climate variability on hydrology in an agricultural catchment on the Loess Plateau of China. J. Hydrol., 377, 35-42.

Liakatas A., Clark J.A., and Monteith J.L., 1986. Measurements of the heat balance under plastic mulches. Part I. Radiation balance and soil heat flux. Agric. For Meteor., 36, 227-239.

Mehlitz T., Yildiz I., Kelly S.F., and Hardin C., 2008. Simulated effects of reflective mulch on energy and water conservation in semi-arid central California greenhouses. Acta Hortic., 797, 307-313. 
Tarara J.M., 2000. Microclimate modification with plastic mulch. HortScience, 35, 169-180.

Tarara J.M. and Ham J.M., 1999. Measuring sensible heat flux in plastic mulch culture with aerodynamic conductance sensors. Agric. For Meteor., 95, 1-13.

Twine T.E., Kustas W.P., Norman J.M., Cook D.R., Houser P., Meyers T.P., Prueger J.H., Starks P.J., and Wesely M.L., 2000. Correcting eddy-covariance flux underestimates over a grassland. Agric. For. Meteorol., 103, 279-300.

Voogt J.A. and Grimmond C.S.B., 2000. Modeling surface sensible heat flux using surface radiative temperatures in a simple urban area. J. Appl. Meteor., 39, 1679-1699.
Wang L.X., Good S.P., and Caylor K.K., 2014. Global synthesis of vegetation control on evapotranspiration partitioning. Geophys. Res. Lett., 41, 6753-6757.

Watanabe T. and Mizutani K., 1996. Model study on micrometeorological aspects of rainfall interception over an evergreen broad-leaved forest. Agric. For Meteor., 80, 195-214.

Yang Q.D., Zuo H.C., Xiao X., Wang S.J., Chen B.L., and Chen J.W., 2012. Modelling the effects of plastic mulch on water, heat and $\mathrm{CO}_{2}$ fluxes over cropland in an arid region. J. Hydrol., 452-453, 102-118. 
Supporting Information for

\title{
Changes of surface energy partitioning caused by plastic mulch in a cotton field
}

\author{
Zhipin Ai ${ }^{1,2}$, Yonghui Yang ${ }^{1 *}$, Qinxue Wang ${ }^{2}$, Shumin Han $^{1}$, Yanmin Yang ${ }^{1}$, Quan Wang $^{3}$, \\ and Guoyu Qiu ${ }^{4}$
}

\footnotetext{
${ }^{1}$ Key Laboratory of Agricultural Water Resources, Hebei Laboratory of Agricultural Water-saving, Centre for Agricultural Resources Research, Institute of Genetics and Developmental Biology, Chinese Academy of Sciences, Shijiazhuang 050021, China

${ }^{2}$ Center for Regional Environmental Research, National Institute for Environmental Studies, Tsukuba 305-8506, Japan

${ }^{3}$ Faculty of Agriculture, Shizuoka University, Shizuoka 422-8529, Japan

${ }^{4}$ School of Environment and Energy, Peking University, Shenzhen 518055, China

*Corresponding author: Prof. Yonghui Yang

E-mail: yonghui.yang@sjziam.ac.cn
}

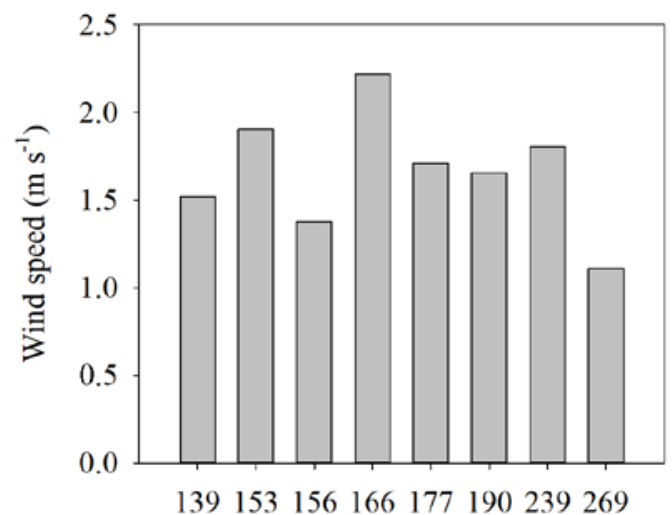

DOY

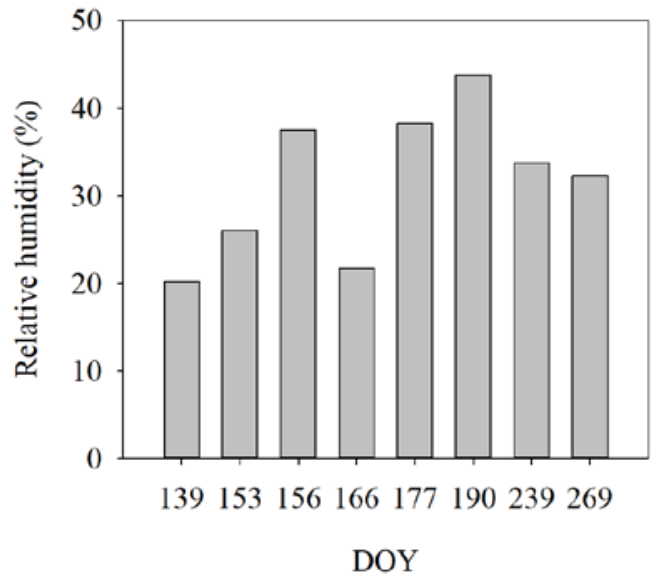

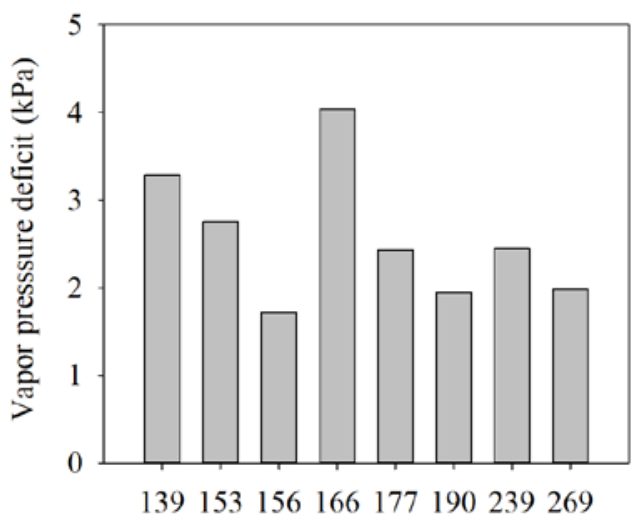

DOY

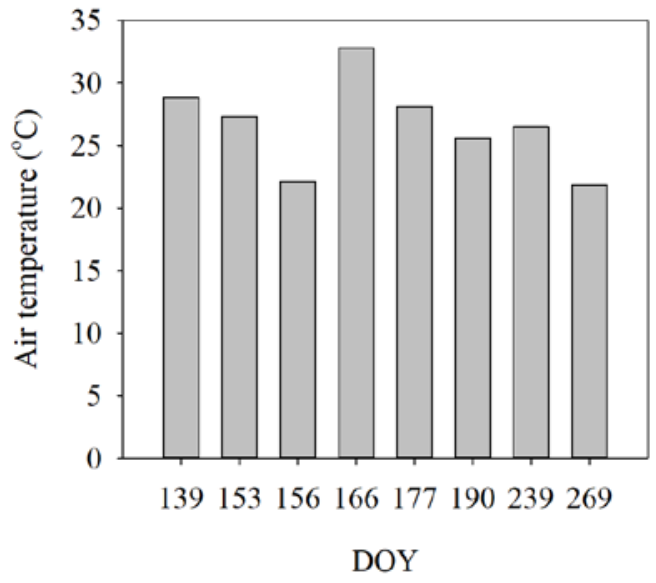

Fig. S1. Basic hydro-meteorological variables on the observation days. 

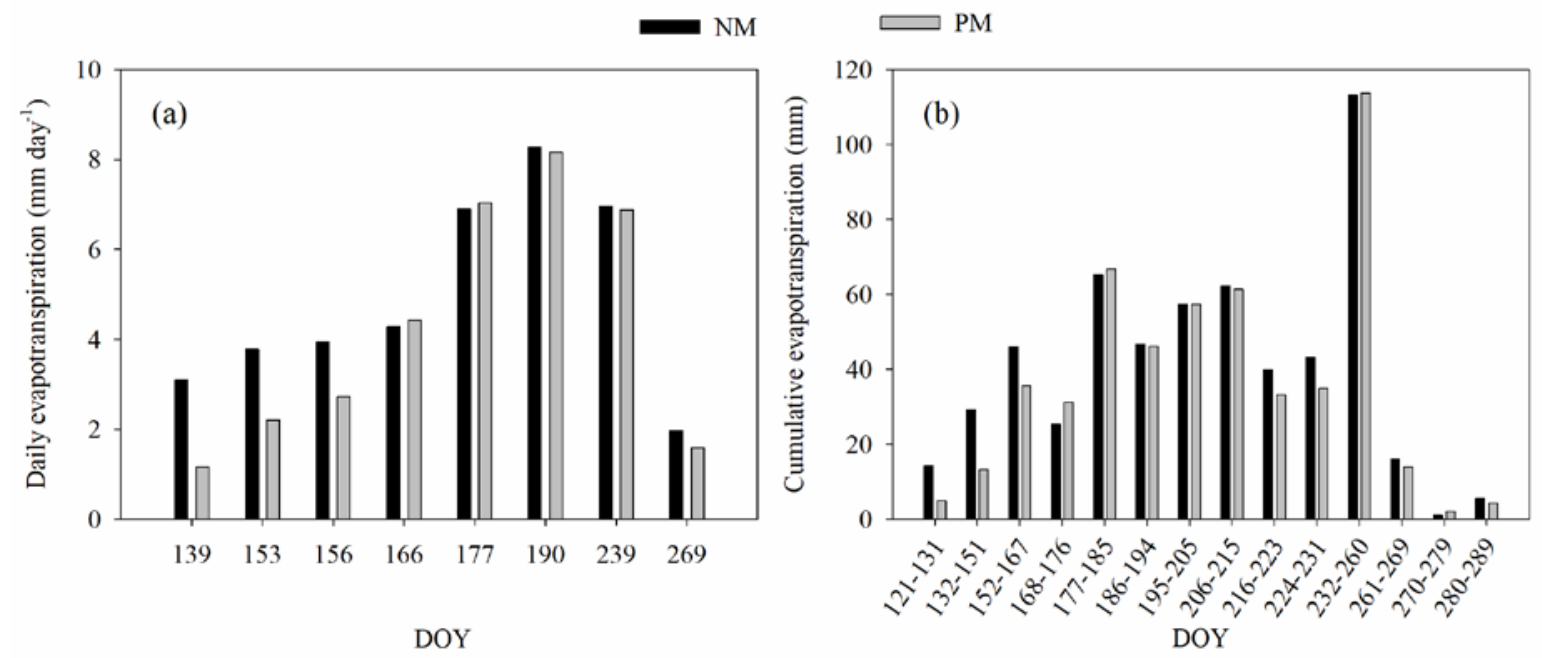

Fig. S2. Comparison of daily evapotranspiration obtained from energy balance analysis (a) at different DOY and cumulative evapotranspiration obtained from water balance analysis (b) at each growth stage under plastic mulch (PM) and non-plastic mulch (NM) conditions.

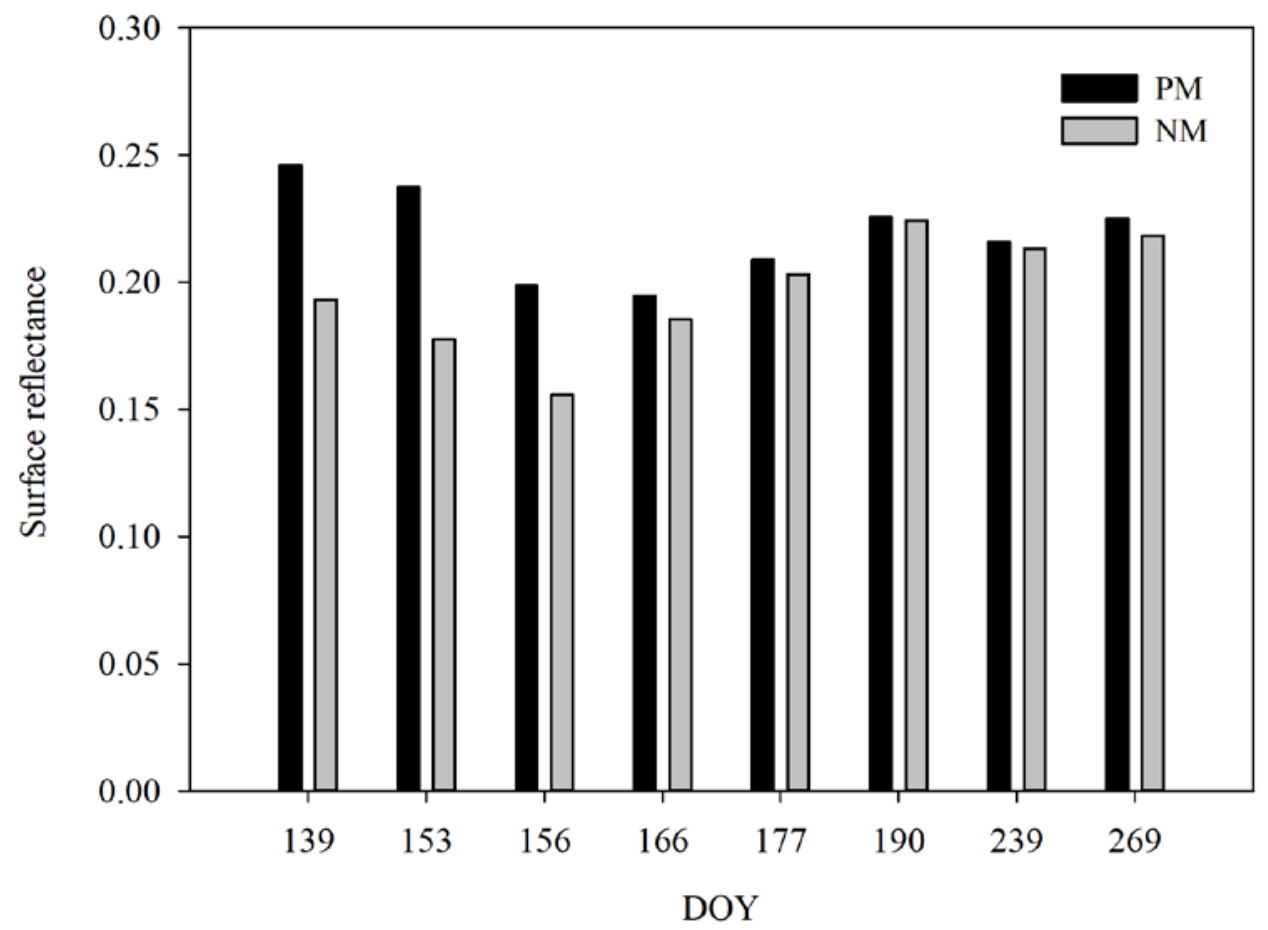

Fig. S3. Surface reflectance under plastic mulch (PM) and non-plastic mulch (NM) treatments at different cotton growth stages. 


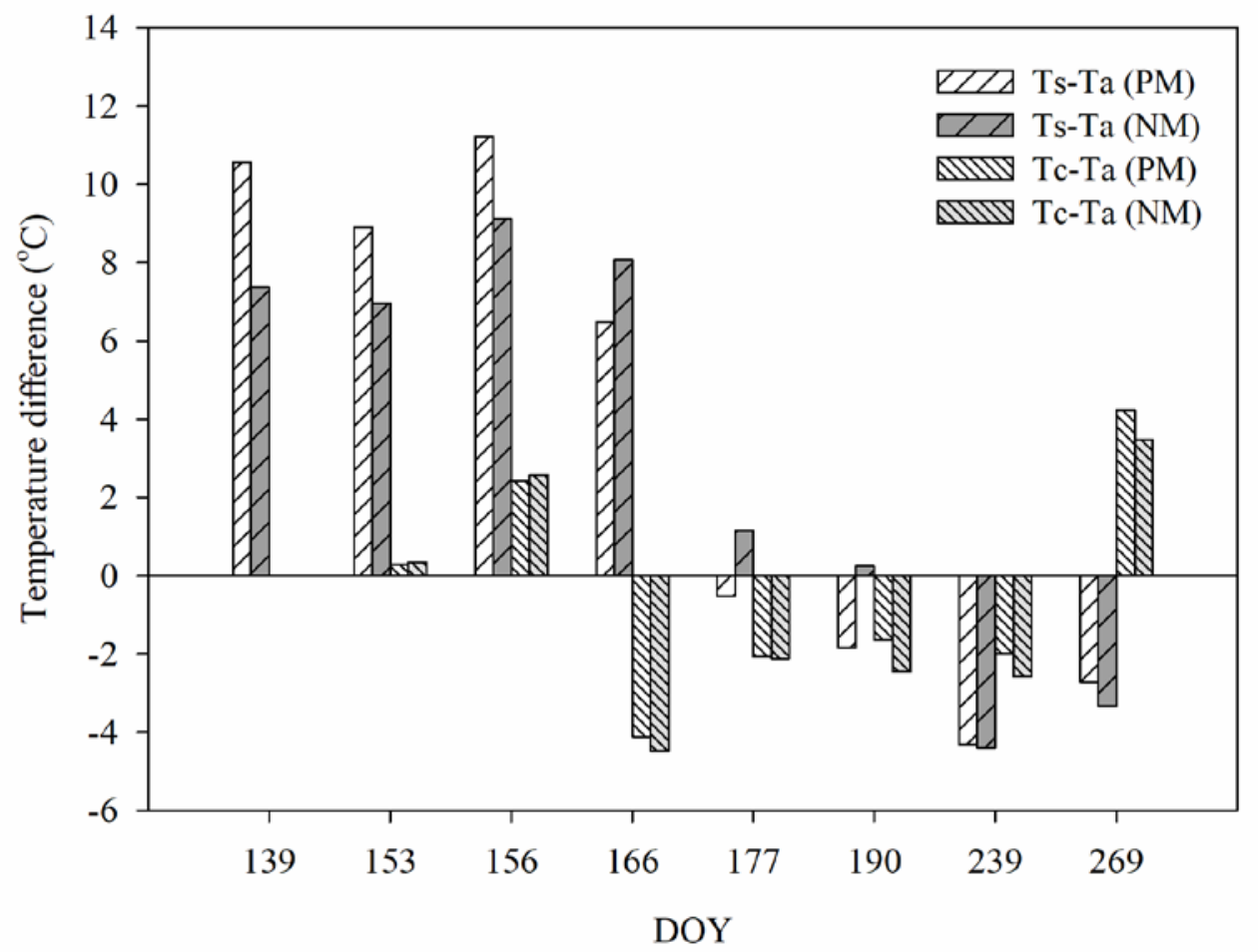

Fig. S4. Differences between surface temperature (Ts) and air temperature (Ta) under plastic mulch (PM) and non-plastic mulch (NM) treatments at different cotton growth stages. 


\section{Calculation methods}

Assuming that canopy energy storage is negligible, surface energy balance in each treatment is expressed as:

$$
\lambda E T=R_{n}-H-G,
$$

where $\lambda$ is latent heat of vaporization $\left(\mathrm{MJ} \mathrm{kg}^{-1}\right), E T$ is evapotranspiration rate $\left(\mathrm{kg} \mathrm{m}^{-2} \mathrm{~s}^{-1}\right), R_{n}$ is net radiation $\left(\mathrm{W} \mathrm{m} \mathrm{m}^{-2}\right), H$ is sensible heat $\left(\mathrm{W} \mathrm{m}{ }^{-2}\right)$, and $G$ is surface soil heat flux $\left(\mathrm{W} \mathrm{m}^{-2}\right)$. Net radiation available for energy partitioning into other forms of energy is the sum of net shortwave and longwave radiation, expressed as:

$$
R_{n}=S_{d}-S_{u}+L_{d}-L_{u} \text {, }
$$

where $S_{d}$ is downward shortwave radiation $\left(\mathrm{W} \mathrm{m}^{-2}\right), S_{u}$ is upward shortwave radiation $\left(\mathrm{W} \mathrm{m}{ }^{-2}\right), L_{d}$ is downward longwave radiation $\left(\mathrm{W} \mathrm{m}^{-2}\right)$, and $L_{u}$ is upward longwave radiation $\left(\mathrm{W} \mathrm{m}^{-2}\right)$. Sensible heat is sensitive to surface temperature and resistance. Sensible heat from canopy $\left(H_{c}\right)$, bare soil $\left(H_{s}\right)$, and mulched soil $\left(H_{m}\right)$ in each treatment is calculated as (Li et al., 2013):

$$
\begin{aligned}
& H_{c}=\frac{\rho C_{P}\left(T_{c}-T_{a}\right)}{r_{a a}+r_{a c}}, \\
& H_{s}=\frac{\rho C_{P}\left(T_{s}-T_{a}\right)}{r_{a a}+r_{a s}}, \\
& H_{m}=\frac{\rho C_{P}\left(T_{m}-T_{a}\right)}{r_{a a}+r_{a s}},
\end{aligned}
$$

where $\rho$ is air density $\left(\mathrm{kg} \mathrm{m}^{-3}\right), C_{P}$ is specific heat of air $\left(\mathrm{J} \mathrm{kg}^{-1} \mathrm{~K}^{-1}\right), T_{c}$ is canopy mean temperature $\left({ }^{\circ} \mathrm{C}\right), T_{a}$ is air temperature at reference level $\left({ }^{\circ} \mathrm{C}\right), T_{s}$ is bare soil surface temperature $\left({ }^{\circ} \mathrm{C}\right), T_{m}$ is mulched surface temperature $\left({ }^{\circ} \mathrm{C}\right), r_{a a}$ is aerodynamic resistance between canopy source height and reference level $\left(\mathrm{s} \mathrm{m}^{-1}\right), r_{a c}$ is bulk boundary layer resistance $\left(\mathrm{s} \mathrm{m}^{-1}\right)$, and $r_{a s}$ is aerodynamic resistance between substrate and canopy source height $\left(\mathrm{s} \mathrm{m}^{-1}\right)$.

Aerodynamic resistance $\left(r_{a a}\right.$ and $\left.r_{a s}\right)$ and bulk boundary layer resistance $\left(r_{a c}\right)$ are calculated as (Shuttleworth and Wallace, 1985; Shuttleworth and Gurney, 1990):

$$
\begin{gathered}
r_{a a}=\frac{1}{k u_{*}} \ln \left(\frac{z-d}{h c-d}\right)+\frac{h c}{n K_{h}}\left\{\exp \left[n\left(1-\frac{z_{o}+d}{h c}\right)\right]-1\right\}, \\
r_{a s}=\frac{h c \exp (n)}{n K_{h}}\left\{\exp \left(\frac{-n z_{o}^{\prime}}{h c}\right)-\exp \left[-n\left(\frac{z_{o}+d}{h c}\right)\right]\right\},
\end{gathered}
$$




$$
r_{a c}=\frac{r_{b}}{2 L A I}
$$

where $k$ is von Karman's constant (0.41), $u_{*}$ is friction velocity $\left(\mathrm{m} \mathrm{s}^{-1}\right), \quad z$ is a reference height (m), $d$ is zero-plane displacement (m), $h c$ is canopy mean height (m), $n$ is extinction coefficient of eddy diffusion, set at 2.5 as cotton height is generally less than $1.0 \mathrm{~m}$ (Brutsaert, 1982), $z_{o}$ is surface roughness length (m), $K_{h}$ is eddy diffusion coefficient at canopy top $\left(\mathrm{m}^{2} \mathrm{~s}^{-1}\right)$, and $r_{b}$ is mean boundary layer resistance ( $\mathrm{s} \mathrm{m}^{-1}$ ), set at $50 \mathrm{~s} \mathrm{~m}^{-1}$ (Brisson et al., 1998).

Friction velocity $\left(u_{*}\right)$ under the neutral conditions is calculated as:

$$
u_{*}=\frac{k u}{\ln \left[\frac{(z-d)}{z_{o}}\right]}
$$

where $u$ is wind speed at reference height $\left(\mathrm{m} \mathrm{s}^{-1}\right)$. Under the non-neutral conditions, friction velocity is calculated as:

$$
u_{*}=\frac{k u}{\ln \left[\frac{(z-d)}{z_{o}}\right]-\Psi_{M}\left(\frac{z-d}{L}\right)}
$$

where $\Psi_{M}\left(\frac{z-d}{L}\right)$ is surface layer stability correction function for momentum, which is calculated with the method described by Sun et al. (2007).

For bare substrate, aerodynamic resistances under the neutral conditions are given by Shuttleworth and Wallace (1985) as:

$$
\begin{gathered}
r_{a s}=\frac{\ln \left(\frac{z}{z_{o}^{\prime}}\right) \ln \left(\frac{d+z_{o}}{z_{o}^{\prime}}\right)}{k^{2} u} \\
r_{a a}=\frac{\ln ^{2}\left(\frac{z}{z_{o}^{\prime}}\right)}{k^{2} u}-r_{a s}
\end{gathered}
$$

Under the non-neutral conditions, aerodynamic resistances is calculated as:

$$
r_{a s}=\frac{\left[\ln \left(\frac{z}{z_{o}^{\prime}}\right)-\psi_{M}\left(\frac{z}{L}\right)\right]\left[\ln \left(\frac{d+z_{o}}{z_{o}^{\prime}}\right)-\psi_{M}\left(\frac{d+z_{o}}{L}\right)\right]}{k^{2} u}
$$




$$
r_{a a}=\frac{\left[\ln \left(\frac{z}{z_{o}^{\prime}}\right)-\psi_{M}\left(\frac{z}{L}\right)\right]^{2}}{k^{2} u}-r_{a s}
$$

Next, the eddy diffusion coefficient at canopy top is calculated as (Brutsaert, 1982):

$$
K_{h}=k u_{*}(h c-d),
$$

An empirical equation is used to calculate the zero-plane displacement and roughness length of the surface as (Brenner and Incoll, 1997):

$$
\begin{gathered}
d=1.1 h \ln \left(1+X^{0.25}\right), \\
z_{o}=z_{o}^{\prime}+0.3 h X^{0.5}, 0<X<0.2 \\
z_{o}=0.3 h(1-d / h), 0.2<X<1.5, \\
X=0.07 L A I
\end{gathered}
$$

where $z_{o}^{\prime}$ is roughness length of bare substrate, taken as $0.01 \mathrm{~m}$ (Van Bavel and Hillel, 1976).

Total sensible heat is calculated as (Li et al., 2013):

$$
H=H_{c}+H_{m} f_{m}+H_{s}\left(1-f_{m}\right),
$$

where $f_{m}$ is the fraction of plastic mulch cover, which is 0.6 in this study.

Surface soil heat flux $(G)$ is measured soil heat flux $\left(G_{z}\right)$ at depth Z (5 cm in this study) plus heat storage term (Fritschen and Gay, 1979):

$$
G=G_{z}+C_{s} \int_{0}^{z_{p}} \frac{\delta T}{\delta t} d z
$$

where $T$ is soil temperature, $t$ is time, and $C_{s}$ is soil volumetric heat capacity. Given the low soil organic matter content, soil volumetric heat capacity is estimated as (de Vries, 1963):

$$
C_{s}=C_{m}(1-\varepsilon)+C_{w} \theta,
$$

where $C_{m}=2$ and $C_{w}=4.18 \mathrm{MJ} \mathrm{m}^{-3} \mathrm{~K}^{-1}$ are heat capacities for minerals and water respectively, $\varepsilon$ is soil porosity, and $\theta$ is soil volumetric moisture. Soil porosity is calculated as:

$$
\varepsilon=1-\frac{\rho_{b}}{\rho_{m}}
$$

where $\rho_{b}$ is bulk density, $1.48 \mathrm{~g} \mathrm{~cm}^{-3}$ in this study, and $\rho_{m}$ is density of minerals, taken as $2.65 \mathrm{~g} \mathrm{~cm}^{-3}$. Surface soil heat flux in each treatment is calculated in the same way as for mulched soil $\left(G_{m}\right)$ and bare soil between two successive plastic films $\left(G_{s}\right)$ as:

$$
G=G_{m} f_{m}+G_{s}\left(1-f_{m}\right) .
$$




\section{References}

Brenner A.J. and Incoll L.D., 1997. The effect of clumping and stomatal response on evaporation from sparsely vegetation shrublands. Agric. For Meteor. 84, 187-205.

Brisson N., Itier B., L'Hotel J.C., and Lorendeau J.Y., 1998. Parameterisation of the Shuttleworth-Wallace model to estimate daily maximum transpiration for use in crop models. Ecol. Modell. 107, 159-169.

Brutsaert W., 1982. Evaporation into the atmosphere, theory, history, and applications. D. Reidel Publishing Company, Dordrecht, Holland.

de Vries D.A., 1963. Thermal properties of soils. In: van Wijk, W.R. (ed.), Physics of Plant Environment. North-Holland, Amsterdam, The Netherlands, pp 210-235.

Fritschen L.J., and Gay L.W., 1979. Environmental Instrumentation. Springer Verlag, New York, pp 216.

Li S., Kang S., Zhang L., Ortega-Farias S., Li F., Du T., Tong L., Wang S., Ingman M., and Guo W., 2013. Measuring and modeling maize evapotranspiration under plastic film-mulching condition. J. Hydrol. 503, 153-168.

Shuttleworth W.J. and Gurney R.J., 1990. The theoretical relationship between foliage temperature and canopy resistance in sparse crops. Q. J. R. Meteor. Soc. 116, 497-519.

Shuttleworth W.J. and Wallace J.S., 1985. Evaporation from sparse crops-an energy combination theory. Q. J. R. Meteor. Soc. 111, 839-855.

Sun Z., Wang Q., Ouyang Z., Watanabe M., Matsushita B., and Fukushima T., 2007. Evaluation of MOD16 algorithm using MODIS and ground observational data in winter wheat field in North China Plain. Hydrol. Processes 21, 1196-1206.

Van Bavel C.H.M. and Hillel D.I., 1976. Calculating potential and actual evaporation from a bare soil surface by simulation of concurrent flow of water and heat. Agric. For Meteor. 17, 453-476. 